\title{
DIRETRIZES CURRICULARES NACIONAIS: \\ IMPACTOS SOBRE OS CURRÍCULOS DE FORMAÇÃO DE PROFESSORES DE EDUCAÇÃO FÍSICA
}

\author{
NATIONAL CURRICULUM GUIDELINES: IMPACTS ON THE CURRICULUM \\ TRAINING COURSE OF PHYSICAL EDUCATION TEACHERS \\ DIRECTRICES CURRICULARES NACIONALES: IMPACTOS EN LOS PROGRAMAS \\ DE FORMACIÓN DE PROFESORES DE EDUCACIÓN FÍSICA
}

Márcia Morschbacher* mm.edufisica@yahoo.com.br

Luiz Fernando Camargo Veronez ${ }^{* *}$

lfcveronez@gmail.com

RESUMO: Este artigo analisa os impactos das Diretrizes Curriculares Nacionais nos currículo dos cursos de formação de professores de Educação Física de duas universidades públicas do Sul do País. Procura demonstrar, a partir de um estudo bibliográfico e documental, a relação desses documentos legais com o atual grau de desenvolvimento das forças produtivas e das relações de produção, explicitando (a) a função de mediação que exercem na adequação da formação dos professores de educação física às atuais demandas do processo de acumulação capitalista e (b) a reprodução das determinações legais e dos marcos teóricos sustentados pelas DCN nos currículos dos cursos de graduação investigados.

PALAVRAS-CHAVE: Formação de professores. Diretrizes Curriculares Nacionais. Reestruturação curricular.

ABSTRACT: This article analysis the impacts of National Curriculum Guidelines in training course of Physical Education Teachers in two Federal Universities on South Country. Aims to demonstrate, as from, a bibliographic and documentary study, the connection of these legal document sand the current level of development of the productive forces and of the relations of production, explaining (a) the mediation function that they operate to the adaptation of the training Physical Education
Teachers to the current demands of the capitalist accumulation processand (b) there production of legal determinations and theoretical frameworks from the DCN in the CV's of under graduate courses investigated.

KEYWORDS: Teacher training. National Curriculum Guidelines. Curricular restructuring.

RESUMEN: Este artículo analiza los impactos de las Directrices Curriculares Nacionales em programas de formación del profesorado de Educación Física en dos universidades públicas en el Sur de Brasil. Trata de demostrar, en una investigación bibliográfica y documental, la relación de estos documentos legales con el nivel actual de desarrollo de las fuerzas productivas y las relaciones de producción, explicando (a) la función de la mediación que desempeñan en la adecuación dela formación de profesores de educación física a las exigencias actuales del proceso de acumulación capitalista y (b) la reproducción delas determinaciones legales y marcos teóricos sostenidos por DCN en los currículos investigados.

PALABRAS CLAVE: Formación del profesorado. Directrices Curriculares Nacionales. Reestructuración curricular. 


\footnotetext{
* Mestre em Educação Física pela Universidade Federal de Pelotas. Doutoranda em Educação pela Universidade Federal da Bahia.

** Doutor em Educação Física pela Universidade Estadual de Campinas. Professor Associado da Escola Superior de Educação Física da Universidade Federal de Pelotas.
}

\section{INTRODUÇÃO}

A década de 2000, no que tange à formação do professor de Educação Física, foi marcada por processos de reestruturação curricular aparentemente assentados na necessidade de adequar o trabalho pedagógico levado a efeito nas universidades, nos cursos de graduação em licenciatura e bacharelado às "reais" demandas dos diferentes espaços de atuação. Na verdade, tratou-se de ajustar a formação desses trabalhadores às "reais" necessidades do capital, que podem ser sintetizadas na expressão "aumento da taxa de retorno de investimentos", ou seja, ampliação das taxas de lucro por meio do aumento da exploração do trabalho. Observa-se que essa tendência não é exclusiva da área da Educação Física, mas geral à formação da classe trabalhadora na etapa atual de desenvolvimento das forças produtivas no capitalismo.

A via de indução desses processos de reestruturação curricular foi um conjunto de marcos regulatórios elaborado e homologado à revelia dos interesses e das necessidades da classe trabalhadora e profundamente alinhado com os setores conservadores da área da Educação Física e com a reforma da educação brasileira - desenvolvida de modo subserviente às "recomendações" do Banco Mundial e do Fundo Monetário Internacional (FMI).

No caso da formação de professores de Educação Física, esses marcos regulatórios são as Diretrizes Curriculares Nacionais (DCN) - a Resolução CNE/CP 01/2002 e a Resolução CNE/CES 07/2004 -, que estabelecem, respectivamente, "os princípios, as condições e os procedimentos" para a formação de professores em geral e para os professores de Educação Física. Uma vez publicados, as Instituições de Ensino Superior (IES) reestruturaram os seus currículos, levando-os em consideração.

Decorridos dez anos da sua homologação, faz-se necessário analisar os impactos dessas DCN na formação dos professores de Educação Física. Esta análise, todavia, demanda retomar aspectos relativos à forma e ao conteúdo das DCN e dos processos de reestruturação curricular desenvolvidos pelas Instituições de Ensino Superior (IES) e explicar estes aspectos tendo em conta o atual grau de desenvolvimento das forças produtivas e das relações de produção. Essa explicação, por sua vez, serve de instrumento para reconhecer os embates entre os distintos projetos de formação defendidos pelas classes sociais antagônicas, em particular, na formação dos professores de Educação Física e as mediações utilizadas pelo capital no direcionamento da formação da classe trabalhadora.

Considerando essas questões, este artigo tem como objetivo analisar os impactos das DCN para a formação dos professores de Educação Física no Brasil, considerando: (a) o atual grau de desenvolvimento das forças produtivas e das relações de produção; (b) a tendência à desqualificação da formação da classe trabalhadora como uma das 
${ }^{1}$ Destaca-se que o não acesso aos bens que resultam desta produção ocorre devido à propriedade privada dos meios de produção e dos produtos do trabalho. Se a produção é universal, o acesso a este não é. condições para a acumulação de capital e para a contenção de classe; (c) os projetos de formação humana em disputa; (d) as DCN como componentes mediadores entre os desígnios do capital e a formação de professores de Educação Física; (e) o conteúdo desses marcos regulatórios, com destaque aos interesses de classe em disputa e às concepções de formação humana subjacentes; (f) o impacto desses marcos regulatórios nos currículo dos cursos de formação de professores de Educação Física de duas universidades públicas do Sul do País (identificadas, neste artigo, como IES1 e IES2, respectivamente).

Trata-se de uma pesquisa documental, cujas fontes de dados são as resoluções CNE/CP 01/2002 e CNE/CES 07/2004, o Projeto Político-Pedagógico (PPP) dos cursos de graduação em Educação Física das instituições investigadas e atas das reuniões de Departamentos, Colegiados, Conselhos e/ou Comissões dessas mesmas instituições.

\section{RELAÇÃO ENTRE O MODO DE PRODUÇÃO CAPITALISTA, OS EMBATES DE PROJETOS DE FORMAÇÃO, AS DCN E OS PROCESSOS DE REFORMA CURRICULAR}

Tendo em vista que, para determinadas formas de relação dos homens entre si, com a natureza, com os instrumentos de trabalho e com os produtos do seu trabalho (em uma palavra, a determinado modo de produção da existência), corresponde determinada superestrutura jurídica, política, filosófica, artística etc., que mantém com esse mesmo modo de produção uma relação de determinação recíproca (MARX, 2008; MARX; ENGELS, 2007). Pretende-se explicar as DCN e os processos de reforma curricular a partir do atual grau de desenvolvimento das forças produtivas e das relações de produção.

Marx (2008), em "Contribuição à Crítica da Economia Política", aponta um fator essencial a ser considerado na análise da realidade: em um dado grau de desenvolvimento do modo de produção da existência, as relações de produção, até então fator de impulso ao desenvolvimento das forças produtivas, tornam-se um obstáculo a esse desenvolvimento.

$\mathrm{Na}$ atual conjuntura, em que as forças produtivas alcançaram um vertiginoso desenvolvimento, no qual a humanidade é capaz de produzir a existência humana de modo universal ${ }^{1}$, as relações capitalistas de produção bloqueiam o desenvolvimento das forças produtivas e, em alguns casos, chegam a destruí-las. Esta contradição entre as forças produtivas e as relações de produção acirra a luta de classes e evidencia com maior intensidade as contradições inerentes ao modo de produção capitalista. À guisa de exemplo: em nome da acumulação capitalista, a força de trabalho (que é força produtiva) é violentamente aviltada pela redução de postos de trabalho, cortes salariais e de direitos, flexibilização e precarização do trabalho, 


\footnotetext{
${ }^{2}$ Acerca dos processos de elaboração da Resolução CNE/CP 01/2002, ver Morschbacher (2012); e da Resolução CNE/CES 07/2004, ver Morschbacher (2012) e Lemos et al. (2012).
}

desmantelamento dos serviços públicos, desqualificação da formação etc.

Além da intensificação da extração de mais-valia pelas vias absoluta e relativa, trata-se agora de reduzir os "custos" com o trabalho como uma das condições (senão a principal, atualmente) da acumulação de capital em certo patamar. Tem-se, destarte, mudanças na organização do trabalho (veja-se o caso da produção de acordo com a demanda), nas relações trabalhistas (demissões, flexibilização das leis trabalhistas, diminuição dos salários etc.), nos serviços públicos (cada vez mais desmantelados e entregues à iniciativa privada) e na formação dos trabalhadores.

Sobre este último aspecto, a formação, tem-se como principal tendência a sua desqualificação. Essa desqualificação - que tem duplo papel, a diminuição do custo da força de trabalho e a contenção de classe - pode ser evidenciada: (a) no aligeiramento dos cursos; (b) na adoção da flexibilidade, da empregabilidade e das competências como conceitos balizadores da formação; (c) na negação do acesso ao conhecimento clássico e científico; (d) na supervalorização da resolução de problemas, da reflexão sobre a prática e das experiências cotidianas em detrimento do domínio do conhecimento que a humanidade acumulou ao longo da história; (e) na negação da história, da ciência, da possibilidade de conhecimento da realidade e da verdade, entre outros aspectos. Neste modelo de formação, por um lado o capital garante força de trabalho mais ou menos qualificada para os postos de trabalho necessários à acumulação de capital, e, por outro, limita a capacidade dos trabalhadores de explicação e de intervenção organizada na realidade.

Portanto, é com a finalidade de atender à diminuição dos "custos" com o trabalho que a educação brasileira, a partir da imposição dos organismos financeiros internacionais, é reformada a partir de meados da década de 1990 (MELO, 2004). É necessário adequar a formação dos trabalhadores às novas demandas do capital e, desse modo, os processos de formação são revistos com base nas suas exigências mediatas e imediatas, referentes tanto ao desenvolvimento das competências requeridas ao trabalho produtivo quanto à contenção da classe frente a uma realidade em que se acirra a contradição entre a produção coletiva dos bens necessários à existência e sua apropriação privada.

É a esta conjuntura que as DCN que orientam a formação dos professores de Educação Física vêm e têm respondido. Este fato permite considerá-las como elementos mediadores entre os desígnios do capital para afiançar a sua acumulação e a formação dos professores de Educação Física. As decisões tomadas em torno da forma e do conteúdo das DCN têm como objetivo garantir o ajustamento da formação e dos próprios trabalhadores ao atual grau de desenvolvimento do modo de produção capitalista ${ }^{2}$.

Acerca do conteúdo das Resoluções CNE/CP 01/2002 e CNE/CES 07/2004, procura-se analisá-lo a partir de dois 
${ }^{3}$ Sobre o mercado de trabalho em que se dá a intervenção profissional em Educação Física, ver Both (2009) e Lemos (2011). componentes fundamentais: a concepção de formação humana e a divisão da formação entre licenciatura e bacharelado. Esses mesmos componentes serão utilizados para a exposição dos impactos das DCN nos currículos dos cursos de graduação em Educação Física da IES1 e da IES2.

No âmbito de ambos os documentos legais, o desenvolvimento de competências é a "concepção nuclear" na organização, no desenvolvimento e na avaliação dos cursos de graduação em Educação Física (BRASIL, 2002; 2004). Esse marco teórico, que compõe o receituário dos organismos financeiros internacionais para a formação da classe trabalhadora, representa a referência comum da reforma educacional produzida a partir da metade da década de 1990 na educação brasileira.

Assim, para garantir trabalhadores flexíveis, capazes de aprender ao longo da vida, de adaptar-se ao constante movimento do mercado de trabalho, é necessário flexibilizar os processos de formação baseando-os no desenvolvimento de habilidades e competências. Este projeto cumpre uma dupla função: (a) garantir força de trabalho qualificada disputando postos de trabalho (mantendo o rebaixamento do valor da força de trabalho pelo sistema da concorrência entre os trabalhadores) e coagida a "requalificar-se" de acordo com as oscilações do mercado de trabalho e; (b) desqualificar a formação, diminuindo os "custos" da força de trabalho e limitando a capacidade de os trabalhadores explicarem a realidade e intervirem de forma organizada (contenção de classe).

Do ponto de vista pedagógico, a pedagogia das competências enfatiza a dimensão do saber fazer, relegando a um plano inferior uma sólida formação teórica baseada na apropriação do conhecimento historicamente produzido e acumulado pela humanidade. O conhecimento, nessa concepção de formação, restringe-se ou se amplia de acordo com sua utilidade imediata ao desenvolvimento das competências, concebidas como a capacidade do trabalhador em mobilizar o conhecimento, transformando-o em ação. Conforme Martins (2010), a ênfase do ensino no método em detrimento do conteúdo, o saber-fazer, o modelo da resolução de problemas e a reflexão sobre a própria prática, o subjetivismo e o aligeiramento da formação são as principais características dos processos de ensino baseados no desenvolvimento de habilidades e competências. Esses aspectos remetem para uma inequívoca direção: a desqualificação da formação dos trabalhadores.

O perfil perspectivado é o de um profissional capaz de responder às demandas do mercado de trabalho "cada vez mais competitivo e em expansão" (BRASIL, 2004a) ${ }^{3}$. Ao subsumir a formação ao mercado de trabalho, as DCN não colocam em questão a atual configuração desse mercado - superexploração do trabalho, baixa remuneração, desproteção social, entre outros - e visam, predominantemente, a adaptação a esse mercado. 
${ }_{4}$ Não se desconsidera o fato de que este projeto de formação apresenta outros componentes e que este possa se expressar de forma particular em determinadas IES ou regiões do País devido à correlação de forças no interior das instituições, no entanto, devido aos limites do artigo, optou-se por destacar estes dois aspectos (a pedagogia das competências e a divisão da formação).
O segundo ponto a ser destacado diz respeito à divisão da formação entre licenciatura e bacharelado, cujas evidências se encontram no Parecer CNE/CES 058/2004 e na Resolução CNE/CES 07/2004. Esses documentos legais legitimam, no tocante a este aspecto, interesses corporativos e privatistas que se mantiveram relativamente incólumes desde a década de 1980 com a Resolução CFE 03/1987 e que retornam com força na década de 1990 com a criação do Conselho Federal de Educação Física (CONFEF) (DIAS, 2011).

A divisão da formação encontra-se comumente justificada pela apologia à expansão do mercado de trabalho. Afirma-se a diferença entre os locais de atuação profissional dos licenciados e dos bacharéis em Educação Física, em que se requereriam cursos distintos tendo em vista a suposta necessidade de conhecimentos e "competências" distintos a cada local de trabalho (nomeadamente, escolar e não escolar).

Essa divisão reúne consideráveis equívocos de ordem epistemológica e pedagógica, os quais sucumbem em uma análise rigorosa dos elementos determinantes dessa divisão, conforme explicitam os estudos de Cruz (2009), Dias (2011) e Morschbacher (2012), como: a desqualificação da formação, a fragmentação e a negação do acesso ao conhecimento da área, a descaracterização da Educação Física mediante a desconsideração do seu papel social (o acesso sistematizado aos conhecimentos relativos à cultura corporal nos diversos campos de trabalho), a cisão entre as áreas de conhecimento, a dissimulação da luta de classes colocando trabalhador contra trabalhador etc.

A este projeto de formação ${ }^{4}$ contrapõe-se um projeto que expressa a síntese da luta do movimento estudantil e dos trabalhadores em geral e da Educação Física, bem como de investigações assentadas epistemologicamente no marxismo. Trata-se da proposta conhecida como Licenciatura Ampliada, que: (a) sustenta a omnilateralidade como concepção de formação humana; (b) articula-se ao projeto histórico superador das relações capitalistas de produção; (c) defende a sólida formação teórica de base interdisciplinar a partir do acesso ao conhecimento historicamente produzido e acumulado pela humanidade; (d) situa o trabalho pedagógico com a cultura corporal como o elemento unificador dos professores de Educação Física nos diferentes campos de trabalho; (e) busca superar a fragmentação do conhecimento a partir de uma organização curricular baseada em um núcleo curricular comum e em eixos de conhecimento; (f) indica a história como matriz científica e a cultura corporal como objeto da Educação Física (TAFFAREL; SANTOS JÚNIOR, 2010; TAFFAREL, 2012).

Tem-se, portanto, no que tange à formação dos professores de Educação Física no País, o embate entre esses dois projetos de formação, os quais expressam interesses de classe antagônicos. No interior do movimento estudantil, 
dos movimentos de luta social, dos fóruns e eventos científicos e das IES, é visível este embate.

A campanha nacional da Executiva Nacional dos Estudantes de Educação Física (ExNEEF) lançada em 2009 (“Educação Física é uma só: Formação Unificada Já!”), o combate do Movimento Nacional Contra a Regulamentação do Profissional de Educação Física (MNCR) contra a regulamentação da profissão, as reuniões do Fórum Nacional das Licenciaturas com Formação Ampliada, as pesquisas que se posicionam cientificamente pela Licenciatura Ampliada ao analisar os impactos das DCN sobre a formação de professores de Educação Física e possibilidades de trato com o conhecimento a partir da Licenciatura Ampliada (TAFFAREL, 1993; LACKS, 2004; SANTOS JÚNIOR, 2005; CRUZ, 2009; ALVES, 2010; COLAVOLPE, 2010; DIAS, 2010; LEMOS, 2011; MORSCHBACHER, 2012), a implementação de uma proposta de currículo baseada na Licenciatura Ampliada no curso de Licenciatura em Educação Física da Universidade Federal da Bahia (UFBA) em 2011, são expressões contra hegemônicas importantes do embate de projetos de formação humana.

\section{OS IMPACTOS DAS DCN SOBRE OS CURRÍCULOS DOS CURSOS DE FORMAÇÃO DE PROFESSORES DE EDUCAÇÃO FÍSICẢ: O CASO DE DUAS IES}

Procura-se explicitar os impactos das DCN sobre os currículos dos cursos de graduação em Educação Física de duas universidades públicas do Sul do País considerando: (a) concepção de formação humana adotada e; (b) as principais consequências da divisão da formação.

Com a homologação das DCN, as IES são impelidas a reestruturarem os currículos dos cursos de graduação em Educação Física, e, não raras ocasiões, além do curso de licenciatura, passam a ofertar o curso de bacharelado. Este é o caso das duas universidades públicas analisadas. Após a aprovação da Resolução CNE/CP 01/2002, ambas iniciam a discussão em torno da reestruturação curricular dos cursos de licenciatura em Educação Física. Durante este processo, mesmo antes da aprovação da Resolução CNE/CES 07/2004, as duas IES debatem sobre a criação dos cursos de bacharelado.

Os cursos de licenciatura são reestruturados entre 2002-2006 (IES2) e 2003-2006 (IES1), e os cursos de Bacharelado são criados entre os anos de 2004 e 2006 nas duas IES.

A principal justificativa para essa reestruturação é a necessidade de adequação às recentes mudanças na legislação, nomeadamente, às DCN. Esta evidência reforça a função de direcionamento da formação exercida pelas DCN e coloca em questão a autonomia científica e pedagógica das universidades. Nos cursos de bacharelado, ainda identifica-se a afirmação (a) do anacronismo entre as 
${ }_{5}^{5}$ Demonstra-se que o CONFEF tem ingerência, não somente ao nível do processo de elaboração das DCN, mas também das reestruturações curriculares e da criação de novos cursos, aproveitando-se do momento "propício" de reforma do Ensino Superior para difundir como idônea a divisão da formação e a "necessidade" de formar bacharéis em Educação Física para ocupar as parcelas do mercado em franca expansão (como o meio do fitness, das lutas etc.). demandas "da nova realidade da Educação Física" (IES2, 2010a) e da expansão do mercado de trabalho; (b) da incapacidade da formação generalista, instituída pela Resolução CFE 03/1987, atender a essas novas demandas e; (c) da necessidade de sintonia com o CONFEF5 (IES2, 2010a; IES1, 2006).

Acerca da concepção de formação humana adotada a partir da reestruturação curricular, buscou-se dados nos PPP sobre a sua posição em relação às competências e ao modo como esta referência é apropriada e expressa nesse documento, além dos perfis profissionais.

Constata-se que a menção à pedagogia das competências ocorre nos PPP dos quatro cursos. Consoante os documentos:

O egresso, formado pelo Curso de Educação Física: Licenciatura Plena da [IES1], deve construir habilidades e competências gerais e específicas para uma atuação significativa na Educação Básica, com atuação específica na Educação Física (IES1, 2005).

O egresso, formado pelo Curso de Educação Física Bacharelado da [IES1],deve construir habilidades e competências gerais e específicas para uma atuação significativa na Educação não-formal, com atuação específica na Educação Física (IES1, 2006).

Acena-se para um programa curricular que leve em conta o conjunto de competências específicas visando o diagnóstico, o planejamento, a execução, a orientação e a avaliação em diferentes campos temáticos, da ginástica, do esporte, das lutas, da dança e atividades recreativas [...] (IES2, 2010a, p. 17).

E a ênfase para com os conteúdos de ensino, expressos nas ementas, nos programas e nas caracterizações das disciplinas [...] estão em conformidade com o que reza a letra $\mathrm{C}$, do art. ${ }^{\circ} .3$ da Resolução do CNE ${ }^{\circ} .1$ (2002) onde se tem "os conteúdos, como meio e suporte para a constituição das competências" (IES2, 2010b, p. 13).

Evidencia-se que os PPP referem-se às competências de forma consentida, o que pode ocorrer, também, no rol de competências a ser desenvolvido pelos estudantes.

Observe-se, no quadro a seguir que, no caso dos cursos de licenciatura e de bacharelado da IES2 e do curso de bacharelado da IES1, as competências indicadas fundam-se predominantemente na Resolução CNE/CES 07/2004. A partir de uma análise dessas competências, cotejadas com a resolução, constata-se:

a) o curso de Bacharelado em Educação Física da IES1 indica competências idênticas às preceituadas por esse ordenamento legal; 
b) o curso de Bacharelado em Educação Física da IES2 acrescenta, substitui e, em certos casos, suprime palavras em seu texto - o que não modifica substancialmente o conteúdo das competências indicadas;

c) o curso de Licenciatura em Educação Física da IES2 delimita as competências a partir da Resolução CNE/ CES 07/2004, circunscrevendo-as à intervenção no espaço escolar.

\begin{tabular}{|c|c|}
\hline \multirow[b]{2}{*}{$\begin{array}{l}\text { Resolução } \\
\text { CNE/CES } \\
\text { 07/2004 }\end{array}$} & $\begin{array}{l}\text { Dominar os conhecimentos conceituais, procedimentais e } \\
\text { atitudinais específicos da Educação Física e aqueles advindos } \\
\text { das ciências afins, orientados por valores sociais, morais, éticos } \\
\text { e estéticos próprios de uma sociedade plural e democrática. }\end{array}$ \\
\hline & $\begin{array}{l}\text { Pesquisar, conhecer, compreender, analisar, avaliar a realidade } \\
\text { social para nela intervir acadêmica e profissionalmente, por } \\
\text { meio das manifestações e expressões do movimento humano, } \\
\text { tematizadas, com foco nas diferentes formas e modalidades } \\
\text { do exercício físico, da ginástica, do jogo, do esporte, da luta/ } \\
\text { arte marcial, da dança, visando a formação, a ampliação } \\
\text { e enriquecimento cultural da sociedade para aumentar as } \\
\text { possibilidades de adoção de um estilo de vida fisicamente ativo } \\
\text { e saudável. }\end{array}$ \\
\hline \multirow[b]{2}{*}{$\begin{array}{l}\text { Bacharelado } \\
\text { - IES1 }\end{array}$} & $\begin{array}{l}\text { Dominar os conhecimentos conceituais, procedimentais e } \\
\text { atitudinais específicos da Educação Física e aqueles advindos } \\
\text { das ciências afins, orientados por valores sociais, morais, éticos } \\
\text { e estéticos próprios de uma sociedade plural e democrática. }\end{array}$ \\
\hline & $\begin{array}{l}\text { Pesquisar, conhecer, compreender, analisar, avaliar a realidade } \\
\text { social para nela intervir acadêmica e profissionalmente, por } \\
\text { meio das manifestações e expressões do movimento humano, } \\
\text { tematizadas, com foco nas diferentes formas e modalidades } \\
\text { do exercício físico, da ginástica, do jogo, do esporte, da luta/ } \\
\text { arte marcial, da dança, visando a formação, a ampliação } \\
\text { e enriquecimento cultural da sociedade para aumentar as } \\
\text { possibilidades de adoção de um estilo de vida fisicamente ativo } \\
\text { e saudável. }\end{array}$ \\
\hline \multirow{2}{*}{$\begin{array}{l}\text { Bacharelado } \\
\text { - IES2 }\end{array}$} & $\begin{array}{l}\text { Dominar conhecimentos e conteúdos conceituais, } \\
\text { procedimentais e atitudinais específicos da Educação Física } \\
\text { e aqueles advindos das ciências afins, orientados por valores } \\
\text { sociais, morais, éticos e estéticos próprios de uma sociedade } \\
\text { plural e democrática. }\end{array}$ \\
\hline & $\begin{array}{l}\text { Pesquisar, conhecer, compreender, analisar, avaliar a realidade } \\
\text { sociocultural para nela intervir acadêmica e profissionalmente, } \\
\text { por meio das manifestações e expressões da Educação Física, } \\
\text { visando à formação, a ampliação e enriquecimento cultural da } \\
\text { sociedade para aumentar as possibilidades de adoção de um } \\
\text { estilo de vida fisicamente ativo e saudável. }\end{array}$ \\
\hline \multirow[b]{2}{*}{$\begin{array}{l}\text { Licenciatura } \\
\text { - IES2 }\end{array}$} & $\begin{array}{l}\text { Dominar, conhecimentos e conteúdos conceituais, } \\
\text { procedimentais e atitudinais específicos da Educação Física } \\
\text { escolar e aqueles advindos das ciências afins, orientados por } \\
\text { valores sociais, morais, éticos e estéticos próprios de uma } \\
\text { sociedade plural e democrática. }\end{array}$ \\
\hline & $\begin{array}{l}\text { Pesquisar, conhecer, compreender, analisar, avaliar a realidade } \\
\text { sociocultural e educacional, para nela intervir acadêmica e } \\
\text { profissionalmente, por meio das manifestações e expressões } \\
\text { da Educação Física, visando a formação, a ampliação e } \\
\text { enriquecimento cultural da sociedade para aumentar as } \\
\text { possibilidades de adoção de um estilo de vida fisicamente ativo } \\
\text { e saudável. }\end{array}$ \\
\hline
\end{tabular}

Fontes: Brasil (2004a), IES1 (2006), IES2 (2010a, grifo nosso) e IES2 (2010b, grifo nosso).

O PPP do curso de Licenciatura em Educação Física da IES1 explicita que se fundamenta, eminentemente, nas Resoluções CNE/CP 01/2002 e 02/2002 para definir as competências a serem desenvolvidas. Distintamente dos 
demais PPP, esse documento indica competências situadas nas dimensões: sociopolítica, sociocultural, técnico-científica e técnico-profissional:

Para o desenvolvimento do perfil desejado, o curso oferecerá aos graduandos a possibilidade de apropriação de conhecimentos por meio do ensino, da pesquisa e da extensão, permitindo ao licenciado um domínio de competências que perpassam as seguintes dimensões: a) sócio-política, através da abordagem crítico-reflexiva da realidade e do conhecimento; b) sócio-cultural que envolve situações de ensino-aprendizagem em que o aluno e as pessoas envolvidas possam compreender e expressar o real; c) técnica-científica caracterizada através do domínio dos fundamentos científicos do Curso que possam auxiliar na sustentação do desenvolvimento econômico e social; d) técnico-profissional que envolve conhecimentos técnicos e práticas específicas da profissão (IES1, 2005a, grifos no original).

Observa-se, no tocante à apropriação da referência das competências, indicadas as suas particularidades, que os cursos de graduação em Educação Física investigados adotam-na e reproduzem-na de forma consideravelmente inequívoca. Indícios da transcendência desse referencial encontram-se no âmbito das competências propostas pelo curso de Licenciatura em Educação Física da IES1. A utilização da expressão "competências" para designar os conhecimentos a serem dominados (competências técnica-científica e técnico-profissional), contudo, sugere a preocupação com a adequação do PPP aos ordenamentos legais vigentes. No caso dos demais cursos, não está colocada a manifestação de crítica a este referencial - a base é a da adequação a esses marcos legais e às suas referências.

Os perfis profissionais propostos são definidos de acordo com os espaços de trabalho. Assim, o perfil diz respeito ao professor cujo local de trabalho é a Educação Básica ou os espaços não escolares. Ademais, esses perfis são definidos partir da suposta necessidade de compatibilizar o atual momento histórico (representado pelos documentos como isentos de contradições) e a formação dos professores de Educação Física:

Como meta principal do Curso Bacharelado em Educação Física da [IES2], aponta-se para a formação de um profissional que seja atento as necessidades surgidas a partir das emergentes demandas socioculturais de um mundo caracterizado por constantes transformações.[...]Na concepção desta proposta, aos docentes, caberá o papel de ampliação das dimensões dos novos espaços profissionais que estão emergindo. Assim objetiva-se que a ação docente esteja atenta para as 
mudanças da sociedade, na cultura e no mundo do trabalho. Necessita-se de um profissional que efetivamente incorpore essa concepção e possa trabalhar dentro de novas realidades (IES2, 2010a, p. 16).

Este excerto revela-se emblemático à demonstração da reprodução do discurso veiculado pelas DCN, baseado na apologia das transformações da realidade, com um mercado de trabalho em expansão e que necessita de um trabalhador sintonizado com essas novas demandas.

Os PPP dos cursos investigados apresentam a divisão da formação entre licenciatura e bacharelado de forma inequívoca. Esses documentos caracterizam cada curso de graduação e, por conseguinte, diferenciam os perfis profissionais, as competências a serem desenvolvidas, as disciplinas a comporem o currículo (etc.), tendo como parâmetro os espaços de trabalho:

O profissional egresso do Curso de Educação Física: Licenciatura Plena da [IES1] estará habilitado para atuar na: Educação Básica [...]; Secretarias municipais, estaduais e nacionais voltadas à área da Educação Física. (IES1, 2005).

Assim, o curso de Licenciatura em Educação Física da [IES2] objetiva a formação de professores para trabalhar na Educação Física escolar. (IES2, 2010b, p.17).

O profissional egresso do Curso de Educação Física - Bacharelado da [IES1] estará habilitado para atuar: Em academias de ginástica [...]; em clubes sociais [...]; na educação formal, através de "escolinhas de esportes"; na promoção e organização de eventos esportivos; em instituições públicas ligadas aos esportes; em instituições públicas ligadas à saúde; em instituições e órgãos públicos e privados com pesquisas nas áreas de saúde e esportes; em hotéis, cruzeiros e órgãos turísticos [...]; como autônomo [...]; em clínicas de reabilitação, hospitais e unidades básicas de saúde. (IES1, 2006).

Acena-se para um programa curricular que leve em conta o conjunto de competências específicas visando o diagnóstico, o planejamento, a execução, a orientação e a avaliação em diferentes campos temáticos, da ginástica, do esporte, das lutas, da dança e atividades recreativas, de aprofundamento tais como: treinamento físico-desportivo, atividades físico-esportivas na perspectiva do lazer; gestão e administração de empreendimentos de atividades em diferentes perspectivas; promoção de cultura, de educação e de saúde e inserção em outros campos emergentes. (IES2, 2010a, p. 17). 
A reforma dos cursos de licenciatura, orientada pela Resolução CNE/CP 01/2002, também é utilizada como justificativa para a divisão da formação. De acordo com os PPP dos cursos de Bacharelado:

A criação do presente Curso de Bacharelado em Educação Física originou-sedas mudanças necessárias no antigo currículo do curso de licenciatura, decorrentes das orientações dos pareceres do CNE $n^{\circ} .9$ (2001) e $n^{0}$. 138(2002) e de posteriores resoluções do CNE. (IES2, 2010a, p. 11).

Considerando-se a necessidade de melhor definir a formação dos nossos profissionais e que esta seja coerente também com o momento que vivemos, quando as licenciaturas das diferentes carreiras acadêmicas das universidades brasileiras se viram forçadas - pelas resoluções 01 e 02/2002- a se reformular, produzindo assim um "vácuo" sobre a formação de profissionais que poderiam/ deveriam atuar em outras frentes que não o ambiente escolar. (IES1, 2006).

Demonstra-se, ainda, que, do mesmo modo que as DCN procuram se sustentar no argumento em torno da necessidade de formação de professores adaptados e preparados para a intervenção no mercado de trabalho em expansão, os PPP dos cursos investigados reproduzem-no e utilizam-no como justificativa e referência aos processos de reforma curricular e para a divisão da formação. A referência à nova realidade da Educação Física e ao mercado de trabalho diz respeito à expansão da esfera da atividade física, da saúde, do lazer e do treinamento no setor privado a partir da década de 1980. Quando associado também a essas atividades garantidas pelo setor público, é nomeado de modo genérico como "locais de trabalho não escolares" e é tomado pelo CONFEF como o seu principal trunfo para justificar a regulamentação da profissão e a divisão da formação entre licenciatura e bacharelado (o que se expressa também nas DCN e nas instituições analisadas). Neste ínterim, o CONFEF sustenta que são necessários cursos distintos devido à demanda distinta de conhecimentos para a intervenção profissional nos espaços de trabalho escolares e não escolares.

A questão da seleção do conhecimento passa a ser um aspecto central, portanto, a ser considerado nos processos de reestruturação curricular. Trata-se do elemento que permite demonstrar, na prática, a exequibilidade (ou não) da divisão da formação defendida pelos signatários deste projeto de formação.

A partir da análise das ementas das disciplinas obrigatórias dos currículos dos cursos investigados, constata-se que, no processo de seleção do conhecimento, disciplinas são incluídas ou suprimidas (negadas) com base no 
parâmetro dos espaços de trabalho, principal mote utilizado para afiançar a pretendida especificidade dos dois perfis profissionais.

Observam-se, por conseguinte, duas situações essencialmente convergentes para a demonstração da tese da insustentabilidade da divisão da formação:

a) nos cursos de graduação em Educação Física da IES2, constata-se um considerável número de disciplinas obrigatórias que são comuns a ambos os cursos - o que corresponde a $1326 \mathrm{~h} / \mathrm{a}$ de carga horária, de um total de $2.771 \mathrm{~h} / \mathrm{a}$ de conteúdos científico-culturais (disciplinas curriculares, à exceção dos Estágios Curriculares Supervisionados e Prática como Componente Curricular) para o Bacharelado e de 2.380 h/a para a Licenciatura. Tem-se, respectivamente, $56 \%$ e $48 \%$ da carga horária com disciplinas idênticas. No tocante às disciplinas obrigatórias distintas, observa-se que se tratam de disciplinas pedagógicas para a Licenciatura (Fundamentos Sócio-Históricos-Filosóficos da Educação, Teoria e Prática Pedagógica, Práticas Pedagógicas na Educação Física até a $5^{\text {a }}$ Série etc.) e, para o Bacharelado, componentes como Aspectos Nutricionais em Educação Física, Legislação Esportiva e Organização da Educação Física, Atividades de Academia etc.

b) Os cursos de Licenciatura e de Bacharelado em Educação Física da IES1 apresentam maior diferenciação entre as disciplinas obrigatórias. Tem-se, aproximadamente, 555 h/a em disciplinas com ementas idênticas - correspondendo, respectivamente, a 21\% e $19 \%$. As disciplinas distintas, na Licenciatura, referem-se à área educacional (Políticas Públicas e Gestão na Educação Básica, Fundamentos Históricos, Filosóficos e Sociológicos da Educação etc.) e à Educação Física escolar (Currículo em Educação Física, Ludicidade e Educação Física, Capoeira na Escola etc.); e no Bacharelado, Ginástica de Academia, Psicologia do Esporte e Exercício, Administração e Gestão do Esporte, Treinamento Desportivo etc. Evidenciam-se, ainda, disciplinas cujos conteúdos das ementas são consideravelmente semelhantes e diferenciam-se em uma de suas unidades, ocasião na qual se aborda a escola ou o espaço não escolar e/ou, ainda que com ementas idênticas, apresentam maior ou menor carga horária para a Licenciatura ou para o Bacharelado - Aprendizagem Motora, Educação Física e Necessidades Educacionais Especiais, Didática da Educação Física etc.

A partir desses dados, identifica-se uma tendência associada à divisão da formação: a dificuldade da diferenciação dos conteúdos específicos a cada curso para além do critério dos locais de trabalho, como já assinalado por Taffarel e Santos Júnior (2010). Esta tendência se expressa de forma diferenciada nas instituições investigadas. Se na IES2 tem-se dois currículos em que cerca de 50\% das 
${ }^{6}$ Não é possível, nos limites deste artigo, detalhar o prosseguimento do debate em torno dos currículos nas IES investigadas. Entretanto, tem-se em ambas as IES tanto ajustes e/ou reformas (de curto e médio prazo) discutidos e implementados relativos aos $\mathrm{PPP}$, às disciplinas, à regulamentação dos Estágios Supervisionados e dos Trabalhos de Conclusão de Curso etc. quanto o debate em torno da unificação da formação e, particularmente na IES1, a deflagração de um novo processo de reestruturação, tendo como referência a Licenciatura Ampliada. disciplinas são idênticas, na IES1 os dois currículos apresentam-se extremamente diferenciados entre si, o que intensifica a negação de conhecimentos a que, necessariamente, leva à divisão da formação.

Do ponto de vista epistemológico, ao dividir-se a formação, tem-se a fragmentação da área da Educação Física, na medida em que se supõe a existência de dois corpos de conhecimentos, um referente ao bacharelado e o outro à licenciatura (TAFFAREL; SANTOS JÚNIOR, 2010). Tem-se dois cursos de graduação a tratar de um mesmo objeto de estudo, considerando-o predominantemente do ponto de vista dos espaços de trabalho. Opera-se uma inversão na relação entre o necessário e o contingente na formação e no trato com o conhecimento - tomam-se os espaços de trabalho (o contingente) como o necessário e o objeto de estudo (o necessário - o aspecto que necessariamente se encontra em questão na intervenção dos professores de Educação Física independentemente dos espaços de trabalho) como o contingente. Do ponto de vista pedagógico, tem-se a fragmentação e a negação do conhecimento, o que implica na dificuldade de que os estudantes tenham uma visão de conjunto da área e dos diferentes aspectos (econômicos, políticos, epistemológicos, pedagógicos etc.) que a permeiam ${ }^{6}$.

Desse conjunto de questões, tendo como base fundante dessa crítica a proposição de uma formação omnilateral, enuncia-se a insustentabilidade da divisão da formação entre licenciatura e bacharelado. Trata-se de considerar, primariamente, que "[...] o que define a profissão são determinadas necessidades ou demandas sociais que podem ou não estar contempladas no processo de formação" (TAFFAREL; SANTOS JÚNIOR, 2010, p. 35). Essa necessidade ou demanda social é o trabalho pedagógico com a cultura corporal. O desafio é formar os professores de Educação Física com uma consistente base teórica que permita a estes, nos diferentes espaços de trabalho, "[...] contextualizar sua intervenção e a partir daí que seja capaz de dosar, garantir uma sequência lógica e sistematizar o conhecimento que será tratado" (TAFFAREL; SANTOS JÚNIOR, 2010, p. 38). Este é um dos parâmetros a partir dos quais a Licenciatura Ampliada propõe o trato com o conhecimento na formação dos professores de Educação Física.

\section{CONCLUSÃO}

A desqualificação da formação dos trabalhadores representa uma das estratégias para a manutenção da acumulação de capital e para a contenção da classe trabalhadora. A defesa da adaptação ao mercado de trabalho, de profissionais capazes de inserir-se neste de modo competitivo, a formação fundada na pedagogia das competências, na sonegação do conhecimento clássico, na divisão da formação entre licenciatura e bacharelado etc., evidenciam a tendência da desqualificação da formação dos professores de Educação Física. As DCN respondem a esta tendência 
${ }^{7}$ Não se pode desconsiderar que há, no interior de cada instituição, certa correlação de forças que expressa cada um dos projetos de formação de professores de Educação Física. Entendemos que os resultados de nosso estudo, o qual se concentrou na análise documental, expressam que as posições hegemônicas nas IES investigadas são as do projeto de formação subjacente às DCN. exercendo a função de elementos mediadores entre o capital e os currículos dos cursos de graduação em Educação Física. A relação de relativa subordinação que os cursos de graduação mantêm com as DCN é a expressão desta função de mediação ${ }^{7}$.

Nesse sentido, se por um lado os cursos de graduação, sobretudo ao nível de seus PPP, adaptam-se às DCN e reproduzem no seu interior as determinações e concepções de homem, de formação humana e de sociedade, por outro, tem-se um movimento contra hegemônico que coloca na ordem do dia não somente a crítica radical ao projeto sustentado pelas DCN, mas a luta por outro projeto, nomeadamente o da Licenciatura Ampliada. Esta luta se expressa nas ações do Movimento Estudantil e do MNCR e no interior das universidades e da área da Educação Física, na medida em que o embate entre esses projetos coloca em questão as bases teóricas e as concepções de homem, formação humana, ciência e sociedade a partir das quais a formação dos professores e a própria área tem se desenvolvido e qual destas pode melhor responder à atual conjuntura do ponto de vista dos interesses da classe trabalhadora. Este é um dos saldos das DCN após dez anos da sua homologação, o qual resulta da sua contraditória função de mediação a serviço do capital e do acirramento do embate com o projeto de formação humana sustentado pela Licenciatura Ampliada.

Os desafios, colocados ao Movimento Docente, ao Movimento Estudantil, ao MNCR, aos intelectuais orgânicos da classe trabalhadora no que diz respeito à formação dos professores de Educação Física, persistem e colocam como demandas candentes a revogação das atuais DCN e a consideração da posição desses segmentos na elaboração de diretrizes à formação, a garantia do princípio constitucional da autonomia científica e pedagógica das universidades, o aprofundamento do debate sobre a Licenciatura Ampliada e a sua base teórica, o desenvolvimento de pesquisas sobre as possibilidades de trato com o conhecimento a partir dessa proposta, a intensificação dos processos de reconceptualização curricular a partir da Licenciatura Ampliada, a resistência aos ataques a esta proposta e à sua base teórica, o fortalecimento do movimento estudantil e do movimento docente e o combate à ingerência do CONFEF na formação e na intervenção dos professores de Educação Física.

\section{REFERÊNCIAS}

ALVES, Melina Silva. Divisão social do trabalho e alienação na formação de professores de educação física da UFS: o estágio supervisionado/prática de ensino enquanto síntese dialética dos projetos em disputa. 2010. 142f. Dissertação (Mestrado em Educação)- Núcleo de Pós-Graduação em Educação, Universidade Federal de Sergipe, São Cristóvão, 2010. 
BOTH, Vilmar José. Mudanças no mundo do trabalho e suas mediações na educação física. 2009. $121 f$. Dissertação (Mestrado em Educação Física)- Escola Superior de Educação Física, Universidade Federal de Pelotas, 2009.

BRASIL. Resolução CNE/CES o7/2004, de 31 de março de 2004. Institui as DCN para os cursos de graduação em Educação Física, em nível superior de graduação plena. Brasília, 2004.

Resolução CNE/CP o1/2002, de 18 de fevereiro de 2002. Institui as DCN para a Formação de Professores da Educação Básica, em nível superior, curso de licenciatura, de graduação plena. Brasília, 2002.

COLAVOLPE, Carlos Roberto. Sociedade, educação e esporte: a teoria do conhecimento e o esporte na formação de professores de educação física. 2010. 234f. Tese (Doutorado)- Faculdade de Educação, Universidade Federal da Bahia, Salvador, 2010.

CRUZ, Amália Catharina Santos. O embate de projetos na formação de professores de Educação Física: além da dualidade licenciatura - bacharelado. 2009. 151f. Dissertação (Mestrado em Educação)- Centro de Ciências da Educação, Universidade Federal de Santa Catarina, Florianópolis, 2009.

DIAS, Fernanda Braga Magalhães. A fragmentação da formação de professores de educação física: minimização da formação sob a ordem do capital. 2011. 293f. Dissertação (Mestrado em Educação)- Centro de Ciências da Educação, Universidade Federal de Santa Catarina, Florianópolis, 2011.

LACKS, Solange. Formação de professores: a possibilidade da prática como articuladora do conhecimento. 2004. 141f. Tese (Doutorado em Educação)- Faculdade de Educação, Universidade Federal da Bahia, Salvador, 2004.

LEMOS, Lovane Maria. Formação e trabalho do(a) professor(a) de Educação Física na formação social capitalista. 2011. 289f. Dissertação (Mestrado em Educação Física)- Escola Superior de Educação Física, Universidade Federal de Pelotas, Pelotas, 2011.

. et al. As contradições do processo de elaboração das diretrizes curriculares nacionais dos cursos de formação em Educação Física e os movimentos de resistência à submissão ao mercado. Movimento, Porto Alegre, v. 18, n. 03, p. 27-49, jul./set. 2012.

MARTINS, Lígia Márcia. O legado do século XX para os professores. In: ; DUARTE, Newton (Orgs.). 
Formação de professores: limites contemporâneos e alternativas necessárias. São Paulo: Cultura Acadêmica, 2010. p. 13-31.

MARX, Karl. Contribuição à crítica da economia política. Tradução Florestan Fernandes. 2. ed. São Paulo: Expressão Popular, 2008.

; ENGELS, Friedrich. A ideologia alemã. Tradução Rubens Enderle, Nélio Schneider, Luciano Cavino Martorano. São Paulo: Boitempo, 2007.

MELO, Adriana Almeida Sales de. A mundialização da educação: consolidação do projeto neoliberal na América Latina - Brasil e Venezuela. Maceió: EdUFAL, 2004.

MORSCHBACHER, Márcia. Reformas curriculares e a formação do (novo) trabalhador em Educação Física: a subsunção da formação à lógica privada/mercantil. 2012. 247f. Dissertação (Mestrado em Educação Física)Escola Superior de Educação Física, Universidade Federal de Pelotas, Pelotas, 2012.

SANTOS JÚNIOR, Cláudio de Lira. A formação de professores de educação física: a mediação dos parâmetros teóricos metodológicos. 2005. 157f. Tese (Doutorado em Educação)- Faculdade de Educação, Universidade Federal da Bahia, Salvador, 2005.

TAFFAREL, Celi Nelza Zulke. A formação do profissional da educação: o processo de trabalho pedagógico e o trato com o conhecimento no curso de Educação Física. 1993. 301f. Tese (Doutorado em Educação)- Faculdade de Educação, Universidade Estadual de Campinas, Campinas, 1993 .

A formação profissional e as diretrizes curriculares do programa nacional de graduação: o assalto às consciências e o amoldamento subjetivo. Revista da Educação Física/UEM, Maringá, v.9, n.1, p.13-23, 1998.

Formação de professores de educação física: diretrizes para a formação unificada. Kinesis, Santa Maria, v.30, n.01, p.95-133, 2012.

; SANTOS JÚNIOR, Cláudio de Lira. Formação humana e formação de professores de Educação Física: para além da falsa dicotomia licenciatura x bacharelado. In: TERRA, Dinah Vasconcellos; SOUZA JÚNIOR, Marcílio. (Org.). Formação em Educação Física \& ciências do esporte: políticas e cotidiano. São Paulo: Aderaldo \& Rothschild; Goiânia: CBCE, 2010. p. 13-47.

IES1. Projeto Pedagógico do Curso de Educação Física Bacharelado. 2006. 
118 DIRETRIZES CURRICULARES NACIONAIS: IMPACTOS SOBRE OS CURRÍCULOS DE FORMAÇ̃̃O DE PROFESSORES DE EDUCAÇÃO FÍSICA

. Projeto Pedagógico do Curso de Educação Física Licenciatura Plena. 2005.

IES2. Projeto Pedagógico do Curso de Bacharelado em Educação Física. 2010a.

Projeto Pedagógico do Curso de Licenciatura em Educação Física. 2010b. 